\title{
A Case of Extraosseous Chordoma at the Cervico-Thoracic Junction
}

\section{S. Noman Zaheer* and Scott F Campbell}

Department of Neurosurgery, Royal Brisbane and Women's Hospital, Butterfield street, Herston, Brisbane

\section{Introduction}

Chordoma is a rare, slow growing tumour with aggressive local behaviour. It is of notocordal origin and arises along the cranio-coccygeal axis. Chordoma accounts for approximately $5 \%$ of all malignant bony neoplasms [1]. About 50\% arise from the sacrococcygeal region, $35 \%$ from the spheno-occipital region and $15 \%$ along the spinal axis [2].

\section{Case Report}

A 27 year old woman presented with an 8 month history of numbness from the lower chest down, urinary hesitancy and poor balance. Examination revealed a spastic paraparesis $(L>R)$, hesitant gait with dragging of the left foot and a sensory level at T12. Radiology revealed a large dumb-bell shaped mass (tumour) markedly expanding the right exit foramina at the C7/T1 level, with both intraspinal and extraspinal components. The intraspinal component caused marked compression of the spinal cord with associated myelomalacia. The extraspinal component of the mass showed homogenous enhancement with degeneration (Figure 1,2). The provisional radiological diagnosis was that of neurofibroma or schwannoma.

The patient proceeded to surgery. The tumour was identified extending out of the right $\mathrm{C} 7 / \mathrm{T} 1$ exit foramina with dorsal nerve

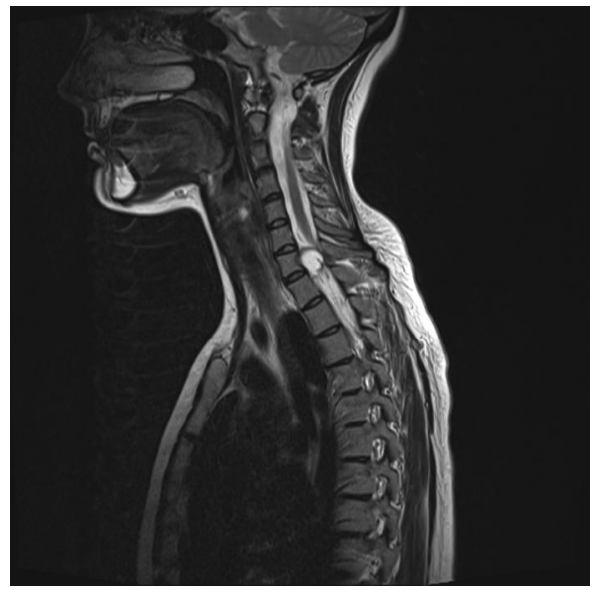

Figure 1: T2 Sagittal view.

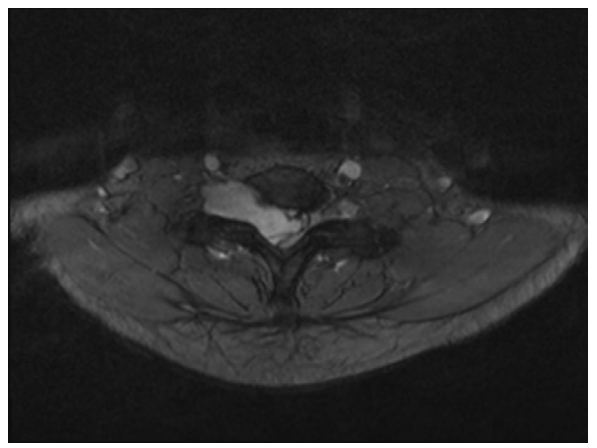

Figure 2: T2 Axial view. roots progressing into the tumour. The medial aspect of the tumour was removed en bloc. Resection of the lateral aspect of the tumour was limited, as it was felt safer in the long term to maintain the integrity of the facet joint at that level.

Histology revealed an extraosseous chordoma and the patient was referred to the oncology/radiotherapy departments for further assessment and management.

\section{Discussion}

Chordomas are slow growing uncommon malignant tumours that arise from the embryonic remnants of the notocord along the craniococcygeal axis. The notochord is associated with the development of the axial skeleton, appearing in the fourth week of gestation and regressing by the seventh week. Incomplete involution of the notocord results in possible development of chordoma. Chordomas are found predominantly in the sacrococcygeal area of the axial skeleton (50\%) and in the spheno-occipital region (35\%). Only $15 \%$ are found along the rest of the spinal axis [2].

The peak incidence of chordoma is in the fifth and sixth decade of life. There is a male preponderance of about 2:1 [1,2]. Symptoms vary and are primarily correlated to the location of the lesion and degree of local invasion. In this reported case the initial presentation was with symptoms of paraparesis, urinary hesitancy and difficulty with walking.

The developmental lesion related to chordoma is the ecchordosis physaliphora, ectopic intradural notochordal remnants [3]. It is uncommon, occurs almost exclusively in the prepontine and clival regions, and is encountered in $0.5 \%$ to $5 \%$ of autopsy specimens [4]. Ecchordosis physaliphoras have been classified as benign developmental lesions [5]. Histologically they are identical to notochordal tissue [3].

Microscopically, typical appearance displays lobulated myxoid stroma containing cords and nests of eosinophilic and physaliferous cells (Figure 3).

\section{Imaging characteristics}

Both CT and MR imaging are used in the evaluation of chordoma, but MR imaging is considered the gold standard [6].

On CT the typical appearance of extraosseous chordomas is a lobular hypo-attenuated soft tissue mass with areas of dystrophic calcification and lytic changes of affected osseous structures $[7,8]$. In this reported case, there was widening of exit foramina.

On MR imaging the features of extraosseous chordoma are similar

*Corresponding author: S. Noman Zaheer, Department of Neurosurgery, Royal Brisbane and Women's Hospital, Butterfield street, Herston, Brisbane, Australia, Tel: 07 3638111; E-mail: drnomanzaheer@yahoo.com

Received November 21, 2011; Accepted January 03, 2012; Published January 07, 2012

Citation: Zaheer SN, Campbell SF (2012) A Case of Extraosseous Chordoma at the Cervico-Thoracic Junction. J Spine 1:106. doi:10.4172/2165-7939.1000106

Copyright: (c) 2012 Zaheer SN, et al. This is an open-access article distributed under the terms of the Creative Commons Attribution License, which permits unrestricted use, distribution, and reproduction in any medium, provided the original author and source are credited. 


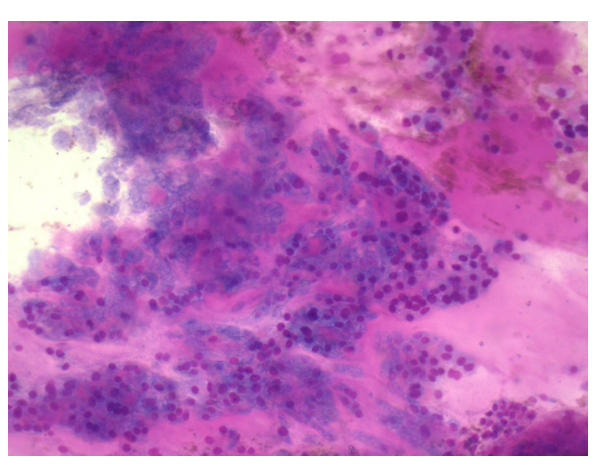

Figure 3: Nests of eosinophilic and physaliferous cells.

to typical skull base chordomas. The lesions are predominantly hyperintense, heterogeneous and demonstrate intra-tumoral septations. These findings suggest that though extraosseous chordomas can have atypical locations, the tumours will continue to demonstrate typical MR imaging characteristics.

\section{Conclusion}

The aim of this case report is to emphasize that it is important to consider chordoma in the differential diagnosis of tumours of this region despite the rarity compared to the benign and potentially curable conditions of neurofibroma and schwannoma. It is important to identify chordoma because it will determine how aggressive to be with resection and the need for postoperative radiotherapy/chemotherapy, along with patient's outcome and expectation. It should be kept in mind that radiological findings can be misguiding.

\section{References}

1. Bjornsson J, Wold LE, Ebersold MJ, Laws ER (1993) Chordoma of the mobile spine. A clincopathologic analysis of 40 patients. Cancer 71: 735-740.

2. Sundaresan N, Galicich JH, Chu FCH, Huvos AG (1979) Spinal chordomas. J Neurosurg 50: 312-319.

3. Ho KL (1985) Ecchordosis Physaliphora and chordoma: a comparative ultra structural study. Clin Neuropathol 4: 77-86.

4. Stewart MJ, Burrow JLF (1923) Ecchordosis physaliphora spheno-occipitalis. J Neurol Psycopathol 4: 218-220.

5. Congdon CC (1952) Benign and malignant chordomas. A clinico-anatomica study of twenty two cases. Am J Pathol 28: 793-821

6. Masui K, Kawai S, Yonezawa T, Fujimoto K, Nishi N (2006) Intradural retroclival chordoma without bone involvement. Neuro Med Chir 46: 552-555.

7. DiFrancesco LM, Castillo C, Temple WJ (2006) Extra axial chordoma. Arch Pathol Lab Med 130: 1871-1874.

8. Larson TC 3rd, Houser OW, Laws ER Jr (1987) Imaging of cranial chordomas. Mayo clin Proc 62: 866-893. 